\title{
On the Strength and Development of the Grain of Wheat (Triticum vulgare).
}

\author{
BY \\ W. E. BRENCHLEY, B.SC. \\ Rothamsted Laboratory. (Lazves Agricultural Trust.)
}

With Plates VIII and IX, and five Figures in the Text.

$T$

HIS investigation on the wheat grain was originally started in 1906 with the idea of approaching the question of the 'strength' of wheat from a biological standpoint. This term 'strength' is one that is by no means easy to define exactly. As is well known, the flours obtained from different species of wheat grown in different localities vary very much in the value they have for bread-making. One flour will produce what the baker calls a 'well-piled' loaf, of good shape, size, and texture ; another may work up into an equally large loaf from the same amount of flour, but of a very bad shape, while yet a third may yield a loaf bad or indifferent both in shape and size, and close and heavy in texture. These differences are all said to be due to the varying 'strength' of the wheat flour. Authorities differ very much in the way they define this term $(1,2)$, but perhaps the best working definition to take at the present time, when the matter is so much debated, is that given by Biffen (3), that 'strength is the capacity of the wheat to produce a large, well-piled loaf'.

Of recent years a great deal of work has been done on the consideration of this point, all more or less from the chemical side, the latest contribution being that of Wood (4), who maintains that there are at least two factors concerned with strength, i. e. the ratio of soluble salts to total proteid, governing the shape of the loaf, and also the sugars and nitrogen-free extract of the flour, controlling the size of the loaf.

Since strength had also been correlated with the date of cutting and the character of the season, an attempt was begun at Rothamsted in the latter part of 1906 to find out whether this varying strength is in any way associated with cytological differences in the wheat grain during the process of ripening, and also whether the diverse manuring of soil in the same locality or the variety of wheat play any part in causing such differences, if they exist. 
Material was examined which had been collected during the summer of I904, killed and fixed in acetic alcohol. This consisted of samples of a typical English wheat, Square Head's Master, taken from two plots in the Broadbalk Field, Rothamsted, one of which has received no manure whatever since 1843 , while the other has yearly a very heavy dressing of nitrogenous manure in the form of ammonium salts; the other samples were Red Fife, a typical strong Canadian wheat, and a Hungarian wheat, very strong when grown in Hungary, both grown at Rothamsted. The grains were collected at irregular intervals between July 21 and August 30 , note being made of the dates of cutting and carting the corn.

When the examination of the material was begun, a great deal of difficulty was experienced in securing the permeation of the grains by paraffin wax, preparatory to sectioning with the microtome. The pericarp of the caryopsis is very tough, and offers a decided obstacle to penetration by such a heavy liquid as melted paraffin wax. Various clearing media were tried-xylol, bergamot oil, paraffin, and cedar wood oil-but it was ultimately found best to cut the grains in half, transfer into the paraffin wax by way of bergamot oil, and then to let them soak in several changes of wax for one to four weeks previous to embedding, according to the age of the grain. Attempts were made to hasten penetration by placing the material under the action of a suction-pump, the tube being led into the embedding oven for the purpose; but no great measure of success attended the experiment.

After sectioning, numerous trials were made with various stains and double stains. It was found that the best results were obtained by overstaining for several hours (five or more) in very dilute Delafield's haematoxylin, then, after washing with tap-water, dipping the slide for a few seconds into acid alcohol ( 5 drops $\mathrm{HCl}$. to $100 \mathrm{cc}$. of 70 per cent. alcohol), finally placing in tap-water till the sections turned blue again. After a light double-staining in orange $G$, the series were dehydrated, cleared in clove oil and xylol, and mounted up in canada balsam. At a later stage of the investigation, considerable use was made of Heidenhain's iron haematoxylin, which gave excellent differentiation when carefully controlled. With this stain the sections were mordanted with the iron alum, and then allowed to remain in the 0.5 per cent. haematoxylin overnight. It was found easier to control the final differentiation by the ferric alum after a long immersion in haematoxylin.

In addition to the microtome series a good deal of sectioning was done by the aid of a Leitz hand-microtome. The ordinary elder pith proved useless for holding such a large and elastic object as a wheat grain, so after various trials it was found that the pith from lime twigs answered the purpose admirably, as it was firm enough to withstand the considerable amount of pressure put upon it, while it was not difficult to cut. These 
sections were carefully kept in series, and were taken at short intervals, each grain furnishing about fifteen sections. Delafield's haematoxylin was used as a single stain in this case, in greater concentration with a shorter immersion.

Three problems presented themselves for consideration with regard to the material so prepared :-

(I) Are any cytological differences, which might affect the strength, to be observed in the developing grains of 'strong' (Red Fife) and 'weak' (Square Head's Master) wheat when grown in the same locality, and therefore subjected to similar climatic conditions?

(2) Are there any cytological differences, indicative of strength, to be found in the developing grains of one variety of wheat (Square Head's Master) when grown in the same field, on similar soil and under the same climatic conditions, but subject to radical differences in manuring ?

(3) Is the reputed difference in strength between grains of the same variety cut 'green' and 'dead ripe' due to cytological changes as ripening proceeds?

Considering these three points separately :-

(I) It has been suggested (3) that varying strength is partly or entirely due to different climatic conditions, but bakehouse experiments have shown that this statement is much too general, as, other things being equal, some strong wheats, e.g. Red Fife, remain strong whatever the climate in which they grow, and vice versa. The Red Fife wheat under consideration had been spring sown, and therefore, date for date, was not at such an advanced stage as the autumn-sown Square Head's Master-in fact, while the Broadbalk wheat was cut on August 5, the Red Fife was left standing till August I5. In comparing the two varieties, due allowance had to be made for this difference in the age of the grain. It was found that the nuclei undergo considerable changes during the progress of ripening of the grain. In the earlier stages they are quite normal and perfect, well formed, and possessing nucleoli. As the grain grows older changes take place, which will be more fully described later under the head of endosperm development, till finally, by the time the grains are matured, the nuclei are very much disorganized in structure, particularly in the deeper-seated cells furthest away from the aleurone layer. The nuclei of the aleurone layer do not undergo this disorganization, and the cell contents seem to remain unchanged when once they are fully organized. The cells of the starchy endosperm which lie nearest to the aleurone layer were found to contain rather more protein than the rest, as was shown by the Xantho-protein reaction. Freshly cut hand-sections were placed in strong nitric acid, and left for a minute or two till they were quite transparent; after washing in water they were transferred to ammonia and left for a few minutes. After a final washing in water, the sections were at once examined under the microscope, when the cells 
of the starchy endosperm lying just underneath the aleurone layer were found to be stained more deeply yellow than the rest, thus indicating the presence of a larger quantity of protein. The manner and extent of infilling of starch were noted, with other details of cell contents and structure, but both the types showed similar phenomena. Altogether it seems that the various points in the history of development are quite parallel in both the strong and weak wheats, and, after due consideration, the conclusion was arrived at that no cytological differences exist under these circumstances which can in any way affect the strength of the grain - at least, no differences that can be observed by the methods used. The information gained as to the developmental history of the wheat grain will be treated fully in the latter part of this paper.

(2) As previously stated, Square Head's Master is an example of a typically weak English wheat, even under the most favourable circumstances, but largely grown because of its good yielding properties.

The crop from the unmanured Plot 3 yields flour of a practically normal strength for the variety (5), which in I9O2 was awarded a 'baker's mark' of 42 for its bread-making capacity. The flour from Plot Io, however, with its very heavy nitrogenous manuring, behaves most abnormally in the bakehouse. Although the grain looks strong, and contains a large percentage of nitrogen, as is shown by analyses, yet the flour proves to be excessively weak when tested just after harvesting, only receiving a nominal baker's mark of I, indicating that it is hardly possible to make bread from it at all. A curious and unaccountable change occurs as time goes on, as flour from the same wheat, when ground and tested again by baking about nine months later, proves to be quite as strong as the ordinary wheat from the Rothamsted Fields (6), but this improvement with age only occurs in the wheat from this one particular plot.

Again, an examination of numerous preparations carried on in the same way as in the elucidation of the first problem failed to reveal any cytological differences in the structure of the two sets of grains--though the material obtained from Plot to seemed to be a trifle less advanced than that from Plot 3, date for date, as the heavy nitrogenous manuring has a tendency to prolong the growing period, and so to slightly delay the progress of maturation.

(3) Examination of grains of the same variety cut 'green' and 'dead ripe' showed certain cytological differences between them. When the grain begins to ripen, changing colour from green to brown, the nuclei in the amyliferous cells of the endosperm are perfect and complete, but as ripening proceeds these nuclei become much disorganized, owing to the pressure exerted by the increasing amount of starch in the cells, and also to the desiccation which goes on as maturation proceeds. With this exception the cytological structure does not seem to undergo any change, and it is hardly 
probable that this disorganization of nuclei has any bearing on the question of strength. As a matter of fact, baking tests do not bear out the idea that grain cut green is stronger than that cut dead ripe, the latter more frequently proving stronger than the former.

To a large extent all these observations were repeated later with material collected in 1907 from the same plots and of the same varieties, with results which corroborated those previously obtained.

To sum up, it seems that so far only negative results have been obtained, and that no cytological distinctions, indicative of strength, present themselves between wheat grains of varying strengths, whether of the same or of different varieties.

Although the original investigation yielded very little result, the examination of the 1904 material seemed to indicate that it would be desirable to pursue the inquiry along different lines, and to study the development of the grain from the time of pollination up to maturity, so this work was undertaken during the summer of 1907 .

\section{DEVELOPMENT OF THE WHEAT GRAIN.}

(a) Preparation of Material.

For the purpose of studying the development it was essential that the grains should be comparable as to age. As is well known, the flowering ear of wheat is an inflorescence composed of numerous flowers of different ages, which therefore 'come into flower' and are pollinated in succession, and not all on the same day. The varieties chosen for investigation in the first place were autumn-sown Square Head's Master from Broadbalk, Plots 3 and 10, and spring-sown Red Fife, from an adjoining field. The first flowers to open and protrude their anthers are the ones in the middle of the groups of flowering glumes situated about four or five down from the tip of the ear.

The plots were watched as the time for flowering drew near, and directly it was seen that the first anthers were hanging out, which always begins on the leading shoots, a staff of workers went through the field and loosely knotted a piece of red wool immediately below each ear which had stamens projecting from one flower. Any ears in which two or three flowers were open in a vertical row were rejected, as these were the forerunners of the general flowering, and were probably a day older than the chosen ears. Thus all the marked ears which were afterwards cut in succession, may be considered to have been of the same age, or with a variation of a few hours only. Two days after this collecting began, and was continued daily at approximately the same hour right up to the time of harvesting, seven weeks later. One grain only was taken from each marked ear, and the one selected was that which had been first pollinated; 
this was easily known by its position and also by the fact that it was usually a trifle larger and better developed than those above and below. To ensure that a second grain was never selected from the same ear the ends of the marking wool were clipped off close to the knot. The material thus collected was fixed in the field, half in Flemming's weak solution and half in acetic alcohol. It was found that immersion in Flemming's solution for any length of time had a decided tendency to blacken the grain; indeed, in the younger stages, this discoloration penetrated right through the tissues. Attempts were made to shorten the time of immersion, even reducing it to half an hour, but while the blackening still occurred to some extent, fixation was imperfect. Much better results were obtained by killing and fixing in acetic alcohol for twenty minutes, washing out well in two or three changes of spirit, and preserving in a mixture of one-third glycerine, two-thirds spirit. As with the 1904 material, the grains were embedded through bergamot oil and cut in microtome series. Various stains were used, including Flemming's triple stain, brasilin, Ehrlich's haematoxylin (also with O. G. or eosin), but the best results were obtained with Heidenhain's and Delafield's haematoxylin (either with or without O. G.).

Material was collected from all the three plots mentioned, but as the sequence of events was parallel in all, attention will be chiefly confined to that obtained from Plot 3, Broadbalk, (Square Head's Master).

\section{(b) Early Stages of Development.}

The ovule of wheat is anatropous, curved on its funicle, so that the micropyle is brought to face inwards towards the stalk of the ear. For the sake of convenience the micropylar end will be consistently referred to as the tip of the grain.

Assuming that pollination in the wheat occurs on the same day that the flower opens, the earliest stage in the material at hand is that taken two days after pollination, though one grain of this date seems a trifle less advanced than the rest. In this case the ovule is cut rather obliquely through the micropyle, and shows a mass of nucellar tissue still present, bounded on the periphery by a single layer of very regularly arranged square-shaped cells, with well-developed nuclei, which eventually merges itself in the tissues of the placenta to which the ovule is attached. Outside this layer are one or two more rows of cells which seem to have broken away from the surrounding pericarp in the process of fixing and preparing. Within the nucellus the boundary line of the embryo-sac can usually be made out, though in places it is disintegrating or destroyed. At the tip of the grain, just where the position of the micropyle is indicated, is a group of two or three nuclei. One of these is a synergid, distinguished by its dense appearance, and there is some indication of the second synergid. 
Below this is the ovum, and in the immediate neighbourhood is a crescentshaped structure, presumably the tip of the pollen-tube, which shows a few well-marked, darkly-staining bodies. Embedded in the nucleus of the ovum, just below the tip of the pollen tube, is an irregular-shaped mass distinguished in the section by its darker colour, which is probably the generative nucleus that has not yet quite lost its entity. The ovum with its nucleus and cytoplasm is bounded by a delicate membrane, a further indication that fertilization has occurred. As Cannon (7) also points out, Koernicke (8) does not mention a division of the generative nucleus in the pollen grain of wheat, and this would be an apparent exception to the statement by Strassburger ('84) that the division of the generative nucleus is a constant character of the grasses. If this were really the case, then it would preclude all possibility of double fertilization occurring in Triticum, though it has been demonstrated by Guignard (9) in Zea mais, which possesses two generative nuclei. Golinski (10), on the contrary, figures two generative nuclei in the pollen grain of wheat, and describes them as being elongated and curved and embedded in a special protoplasm, stating that they are not unlike the Antherozoids of Ferns and Characeae in appearance.

In the ovule under consideration dense cytoplasm appears on the other side of the embryo-sac, in which are embedded two large nuclei, the result of the first division of the definitive nucleus, if we may assume that the polar nuclei have already fused. According to Golinski, the two polar nuclei are at first in close contact with the ovum: before fertilization, however, they pass down into the vicinity of the antipodal cells, after which the ovum is ready to be fertilized. Apparently the polar nuclei fuse to form the definitive nucleus just at the time of fertilization, so it is probable that the two nuclei in question are really the two first endosperm nuclei and not the unfused polar nuclei. The fusion and subsequent division evidently take place very rapidly. Guignard (9) found in maize that the fusion of polar nuclei and the incorporation of the generative nucleus with them takes place in such a short space of time that the phenomenon can very rarely be observed.

The antipodal cells at this stage are still well in evidence, but show traces of incipient disorganization. In Triticum, as in many of the Gramineae, the antipodals are numerous, forming a regular tissue in the embryo-sac adjacent to the placenta. Koernicke (8) indicates the presence of thirty-six antipodals in this case, while Westermaier (11) gives a full account of the literature relating to these cells in the grasses.

The indications are that fertilization normally occurs between one and two days after pollination, as most of the grains taken on the second day after are rather more advanced than the one described. In these, part of the cytoplasm is massed at the micropylar end about the ovum, and the rest, while still remaining in connexion, is gathered round the periphery of 
the embryo-sac, surrounding a central vacuole. Embedded in the lining plasm are, not two, but several nuclei, which are evidently the result of the division of the definitive nucleus, and hence are the early endosperm nuclei. These are quite free, no trace of cell walls appearing. Some series, notably those stained with Ehrlich's haematoxylin and O. G., show the arrangement of nucellar and pericarp tissues very clearly. On the outer side of the regularly arranged boundary of the nucellus is a double layer, forming the inner integument of the ovule. Beyond this are two more rows of cells, thin-walled, and appearing rather crushed in places, which have sometimes remained in contact with the inner integument, sometimes with the inner layer of the pericarp in those preparations in which the ovule has shrunk away from the pericarp. This layer evidently represents the outer integument of the seed, which gradually disappears in the course of development. The pericarp shows on its inner side one or two rows of regularly arranged cells with dense protoplasmic contents, beyond which occurs the largercelled tissue containing much starch. The outer boundary is an epidermis of uniform cells, with much less starch, if any.

By the next day, the third from pollination, evident progress has been made. The fertilized ovum has entered on a temporary resting-stage, and no change has yet occurred in it, while the synergidae have practically disappeared. The central vacuole has enlarged, and the nuclei embedded in the protoplasmic lining have greatly increased in number. These embryonic endosperm nuclei are multiplying at the expense of nutriment obtained from the nucellar tissue, the innermost cells of which have been emptied of their contents and are disorganizing, except at the tip of the grain, where they are being reserved for the future use of the embryo. The cells of the limiting layer of the nucellus have resumed their activitymany of the nuclei are in process of division, and some of the cells are narrow, only about half the normal width, showing that division has occurred, but the daughter-cells have not yet grown to their proper size.

On the fifth day after pollination the first indication of division occurs in the fertilized egg cell. At this stage the future embryo lies at the tip of the grain in a little cul-de-sac formed by the nucellar tissue persisting in this region. In attendance on it is a dense mass of cytoplasm which is full of nuclei, while the protoplasmic lining of the embryo-sac contains very numerous nuclei characterized by the large number of nucleoli they possess ; as many as eight have been counted in some cases (cf. Cannon on Avena fatua, where the nuclei have from three to eight nucleoli). From this point onwards the development of the endosperm and embryo will be considered separately. The limiting layer or epidermis of the nucellus behaves somewhat differently from the rest of the tissue. As previously stated, about three days after pollination the cells of which it is constituted renew their activity, nuclear division beginning again and continuing at a rapid rate, so 
that the growth of the tissue keeps pace with the expansion of the embryosac for some time. At this stage the appearances indicate that this layer may persist in the ripe seed in the form of the aleurone layer, but later sections do not bear this out. The epidermis continues apparently unaltered for some days after the rest of the thin-walled nucellus has been absorbed by the developing endosperm. About a fortnight after pollination, however the epidermal cells lose their contents, just about the same time that the aleurone layer comes into evidence, and the cells get crushed, though the outer and inner walls thicken up and persist in the ripe seed (13).

\section{(c) ENDOSPERM.}

I. Development. It has already been shown that the endosperm arises in the first place by free cell formation, i.e. a large number of nuclei are derived from the definitive nucleus by repeated division, and are embedded in the protoplasm lining the wall of the embryo-sac, no cell walls being formed. During this period the protoplasm seems to be more dense in the immediate neighbourhood of the disorganizing antipodal cells, possibly because, as Koernicke (8) suggests, the developing endosperm is drawing very largely on the substance of the antipodal tissue for its own nutrition. The surrounding nucellar tissue, with the exception of its epidermis or limiting layer, is gradually absorbed, except in the immediate neighbourhood of the fertilized ovum, in which position there is also a large accumulation of protoplasm with many embedded nuclei.

About seven or eight days after pollination a change occurs and the formation of cell walls begins. These start at the periphery of the endosperm and develop inwards very rapidly, till within about two days the endosperm is changed from a mere nucleated protoplasmic layer surrounding a large central vacuole to a definite tissue extending through practically the whole of the embryo-sac. The central vacuole of the embryo-sac fills up first with endosperm tissue at the micropylar end (7), though some sections seem to indicate that the cytoplasm immediately surrounding the embryo does not develop its cell walls till a little later. At first the mass of cytoplasm completely surrounds the young embryo except just at the tip, but as the latter develops it gradually absorbs the endosperm on the outer side away from the furrow, and also the nucellar tissue in the same region, so that it is displaced from its central position to a somewhat lateral one on the outer side of the endosperm. Eventually walls are developed all the way through, but the cells formed from the cytoplasm in the neighbourhood of the embryo retain their dense protoplasmic contents for a long time after the main mass of endosperm tissue begins to appear very poor in protoplasm. Westermaier (11) describes a similar phenomenon as occurring in Zea mais.

Quite early in development the endosperm cells on the ventral side 
opposite the furrow, are marked off from the rest by their smaller size and denser protoplasmic contents. Eventually a peripheral layer of such smaller cells is marked off, appearing on the dorsal side about a fortnight after pollination. This external layer develops into the aleurone layer, which is highly specialized in the cereals, and consists of small regularlyarranged cells with dense protoplasmic contents and well-marked nuclei, which persist unaltered right up to maturity. No starch grains are present, but instead there is a great accumulation of protein matters which are probably of different chemical composition from those in the rest of the endosperm. The cells in the bulk of the tissue, on the other hand, are large, varying much in size and shape. The protoplasmic contents are reduced to a minimum in the ripe grain, being drawn out into a very attenuated reticulum, and the nuclei undergo definite disorganization, as will be seen later. The protein matters are chiefly to be seen in the cells lying just below the aleurone layer, but the most marked feature of the cell contents is the enormous amount of starch deposited as grains of different sizes.

Certain microscopical tests were carried out to ascertain the behaviour of the aleurone layer during the manufacture of flour, two separate sets of wheat flour, specially milled by Mr. A. E. Humphries, from Coxes Lock Mills, Weybridge, being used for the purpose.

In the modern process of roller milling, the wheat grains are gradually reduced by being passed through successive pairs of revolving rollers (14), so that eventually the whole of the central part of the grain is cleared away from the coverings, which form the bran. After each crushing or rolling the finest particles are sifted out and form the various grades of flour, and samples of these, including the bran, were sent to me for investigation. The flours were subjected to close microscopic scrutiny, with and without staining in various ways, in order to find out whether the aleurone cells were ever present in the flour itself. Very seldom indeed could any of these cells, even isolated ones, be observed in the flour of any grade-all the samples could be considered as practically pure in this respect. The reason was obvious when an examination of the bran was undertaken. In the initial processes of cracking or 'breaking' the grain, the aleurone layer had split simultaneously with the fruit-coats, and remained firmly adherent to them; in the subsequent milling the whole of the starchy endosperm tissue was torn away, and ultimately converted into flour of different grades, while the aleurone layer remained behind in small sheets, so to speak, and formed part of the bran. This is probably due to the fact that the junction between the thin-walled cells of the starchy endosperm and the very resistant and thick-walled aleurone cells offers the line of least resistance to the pressure applied during the process of milling.

2. Infiltration of Starch. The deposition of starch in the endosperm 
cells was studied on 1907 material from Plot Io, Broadbalk, by means of series of hand-sections stained with iodine. It was afterwards found that grains from Plot 3 reached a similar stage of development about a day earlier, which is probably due to the fact that the heavy nitrogenous manuring of Plot Io slightly retarded development.

In all the younger stages there is a dense accumulation of starch in the pericarp, which gradually decreases in quantity, being utilized for respiration and possibly for the nourishment of the growing seed. Traces of this pericarp starch linger for a long time at the micropylar end, especially in the neighbourhood of the furrow.

By the ninth day after pollination the endosperm is still incomplete, cell-walls only extending part of the way inwards from the periphery, while as yet there is no vestige of starch.

Rapid progress is now made, for by the next day endosperm structure is nearly complete, except just in the middle of the tissue. Towards the lower end of the grain, one or two cells in the middle of the 'flanks' show minute starch grains in the closest connexion with the nuclei. Lower down rather more cells show this, but the starch all through remains very small and is only in association with the nuclei, never scattered throughout the cells.

By the eleventh day from pollination the endosperm is completely formed and some starch is seen in the

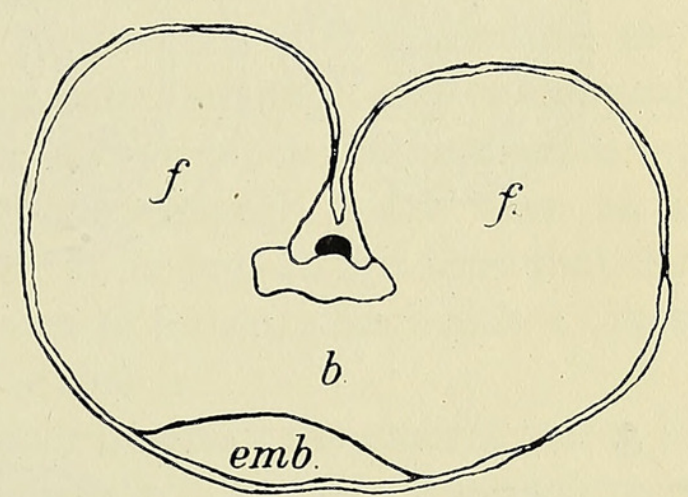

TeXT-FIG. I. Diagram to illustrate position of 'flanks' and 'bridge' in wheat endosperm. $f$. flank; $b$. bridge ; $e m b$. embryo. flanks well up towards the tip. The quantity in the flanks increases gradually as one goes down the grain, and though chiefly associated with the nuclei, the starch eventually begins to get scattered in the cells. At first there is no starch at all in the portion of the endosperm connecting the two flanks across the furrow, which we may call the 'bridge'. Quite late in the series a little starch puts in its appearance across the bridge, but only in the cells on the side nearest to the furrow-none at all occurring on the outer side, except quite at the base of the grain.

The next day, the truelfth from pollination, gives one of the most representative stages in the infilling of the starch in the endosperm. The embryo itseif is still very small and little developed, and in its neighbourhood the endosperm, though quite complete, shows no sign of starch. A good deal of protein matter seems to be present, as a deep yellow coloration is obtained with iodine, both here and in most other series where the reaction is not masked by the deep staining of starch. Proceeding downwards 

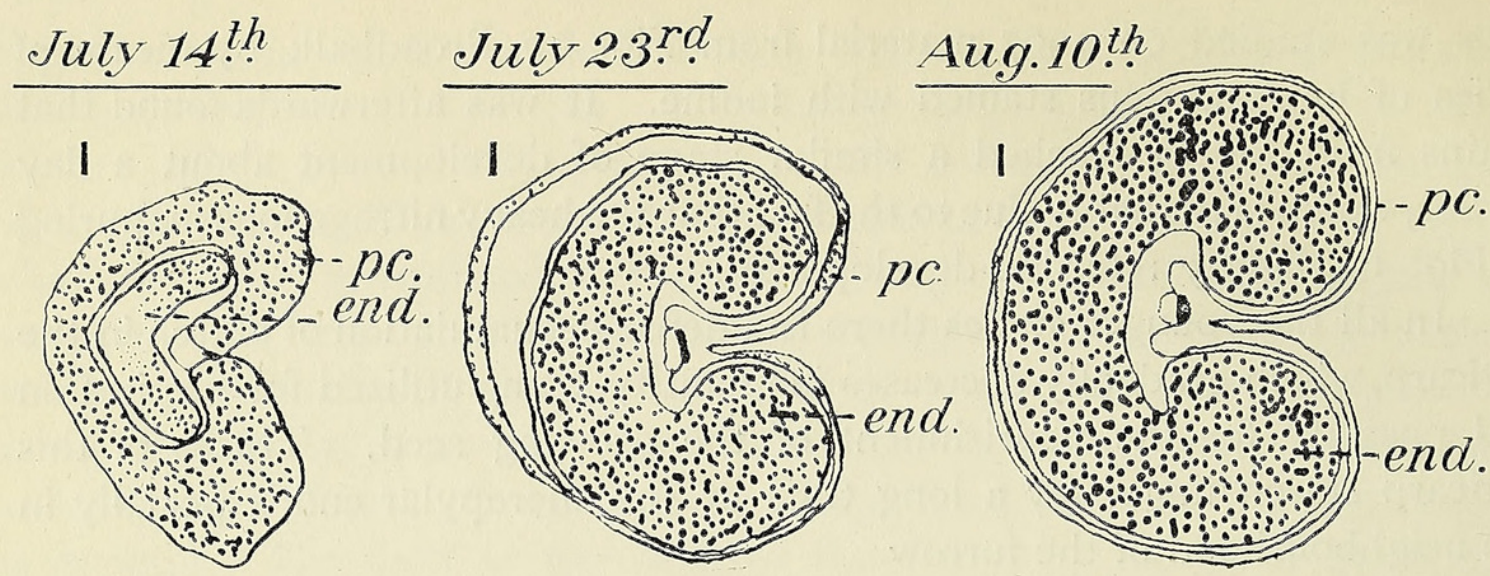

2
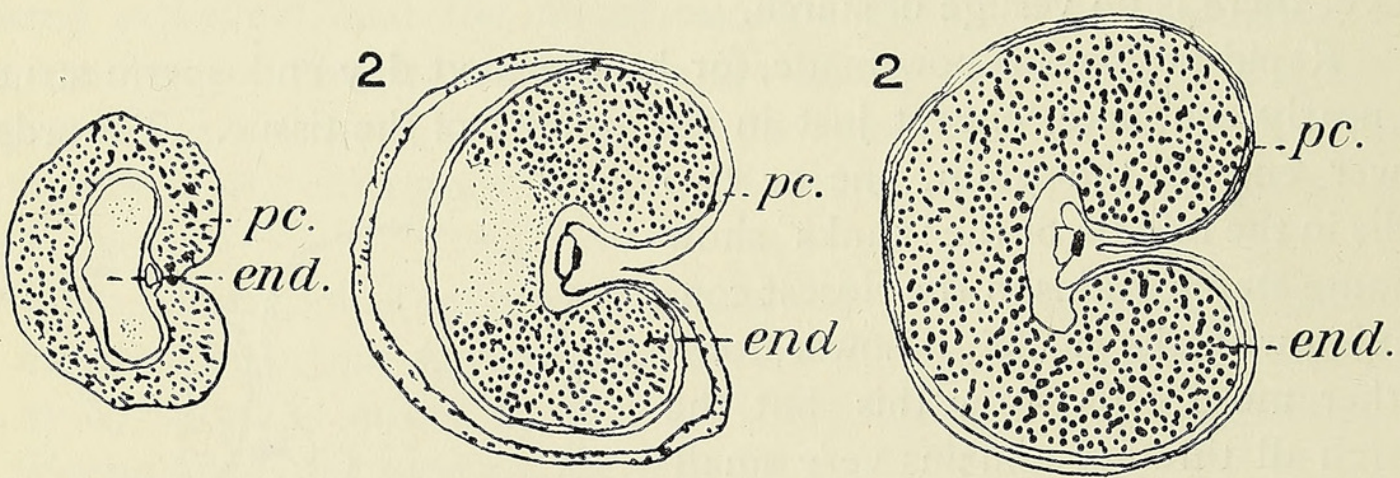

3

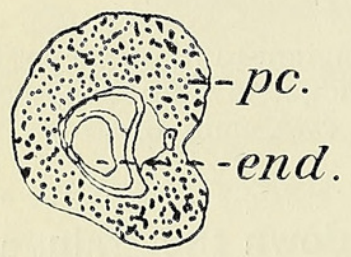

3
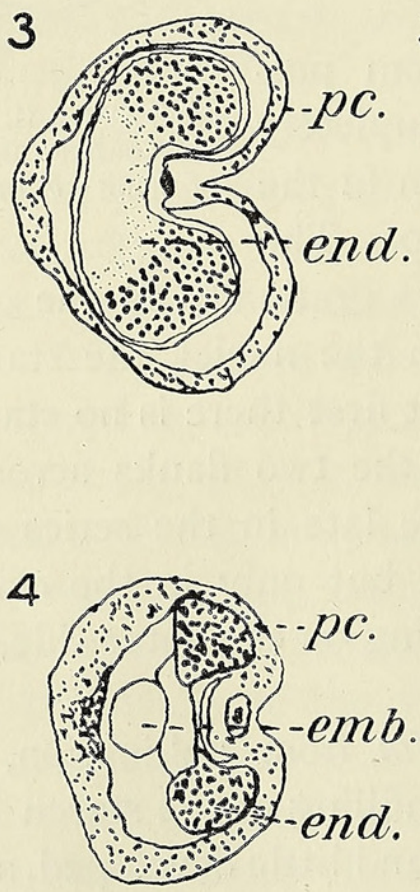
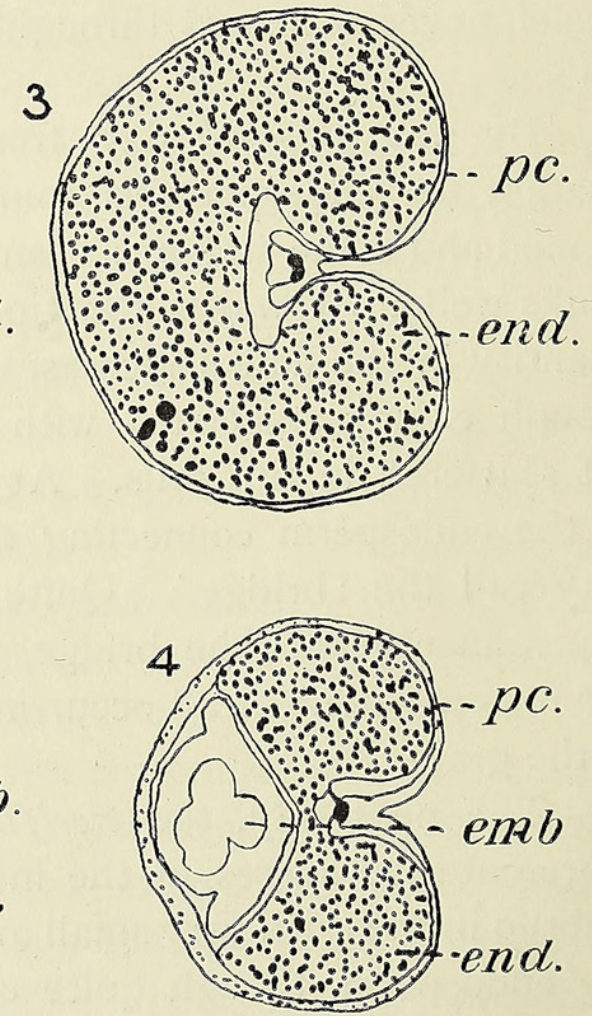

TEXT-FIG. 2. Diagrammatic representation of the infilling of starch into the wheat endosperm at different stages of growth, showing the distribution on July 14, July 23, and August IO-I 2, 2I, and 39 days after pollination. (I) Trans. sect. cut near base of grain, (2) higher up, (3) just below embryo, (4) at level of embryo. emb. embryo; end. endosperm; pc. pericarp, with starch in many cases. Dark shading in endosperm indicates dense starch, light shading scattered starch, and no shading shows its total absence. $\times 9$. 
some cells in the flanks begin to show small starch grains, congregated almost entirely round the nuclei, which are large and well developed, in full activity. Further away from the embryo the starch in the flanks increases in amount, while a certain quantity gradually fills in across the bridge, but is at first confined to the side next the furrow, only spreading outwards lower down the series. At the extreme end of the grain a fair amount of starch is present, though right up to the end there is less towards the outer side of the bridge than in the flanks, or on that side of the bridge next the furrow.

During the next three or four days the infilling of reserve material makes rapid strides. Starch is now found in the flanks right up to the level of the embryo, and at this stage it also occurs across the bridge, next to the furrow. The carbohydrate rapidly extends outwards, till a short distance down the whole endosperm is filled in.

From this time onwards no radical change takes place. The starch appears to get more dense and gradually fills up the cells on the outer side of the bridge adjacent to the embryo. Five weeks after pollination the infilling may be regarded as practically complete, judging by microscopical tests, though there are usually one or two rows of much deformed cells on the outer side destitute of starch all the way through, which have been crushed back by the developing embryo. It is just at this time that the grain begins to change its colour from green to brown, after which it takes about another fortnight to become properly ripe.

When one comes to consider the manner in which the reserve starch is packed into the cells, there are certain points which are somewhat contrary to one's expectations. The wheat ovule is anatropous, and therefore a conducting strand runs up the raphe alongside the seed, at the base of the furrow, and so one would naturally expect that insoluble carbohydrate would first be laid down in the cells at the extreme limit of the grain, as actually happens. The flanks of the endosperm, where the first vestiges of starch occur, continue to keep the lead, as, at any level, it is always the cells in this position which first reveal starch grains. Then, instead of the soluble carbohydrate being carried across the width of the endosperm, and being finally deposited in the first place at the outer edge of the grain, thus leaving a clear passage behind it, the cells which first deposit their starch are those nearest to the furrow, and therefore to the conducting strand. This makes the percolation of the soluble reserves much more difficult, and, judging by the appearance presented by the various series of sections, it seems probable that the infilling does not only take place laterally, but also in an obliquely downward direction. This implies that soluble reserves are brought to a certain point in the conducting strand-thence some probably pass into the endosperm obliquely downwards, filling up the cells at a lower level which have been blocked 
by the deposition of starch in the cells next the furrow at their own level. Part of the remainder of the reserve material so brought passes laterally outwards, and is deposited in the flanks of the endosperm, and eventually the cells next the furrow are filled up, so placing that particular portion of the conducting strand out of action, or rather crippling its activity to a very great extent. It is most probable that a certain amount of percolation can take place through the starch-filled cells next to the

\section{Grams per}

1000 grains.

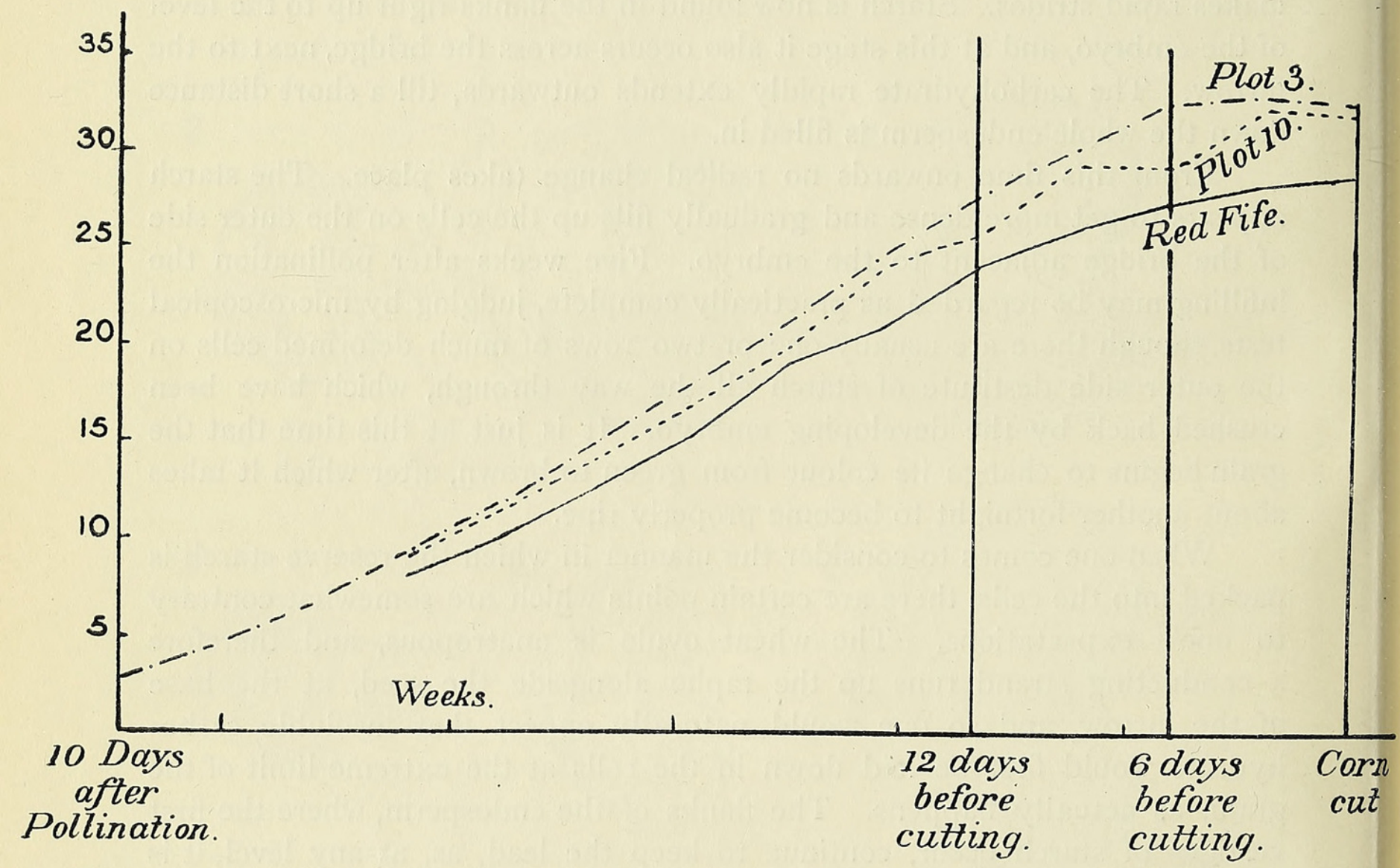

TEX'T-FIG. 3. Curve illustrating the influx of starch into the grain during the course of development.

furrow, as these cells are blocked to the very end of the seed some little while before all the outer cells are filled with starch, but these latter cells fill up very slowly indeed, showing how difficult the percolation must be.

During the year 1907 a good deal of progressive quantitative work, as yet unpublished, was carried out on the wheat grain in the course of development. The 'green and dry weights of $\mathrm{I}, 000$ grains' were ascertained every three days, and formed the basis to which all other calculations of quantitative analyses were ultimately reduced. Determinations were made of the actual amounts of ash, nitrogen, and phosphoric acid in the grain at 
three-day intervals, from about the tenth day after pollination till the time of harvesting.

From these determinations it was possible to make an approximately accurate calculation of the quantity of carbohydrate per I,000 grains - the results of which have been expressed as a curve for each of the three plots. It is readily seen that, at least in two cases, the curve is very smooth and very straight for a period corresponding to about six weeks from the time of pollination, while it flattens off considerably during the last week. This indicates that the infilling of starch goes on very steadily and regularly for about six weeks, the rate of inflow hardly fluctuating at all. Then, shortly before the grain is what the farmer would call 'ripe', this influx practically ceases.

A parallel series of analyses showed that during the whole period of starch deposition, protein matters are entering the endosperm at the same time, but the stains used to place the starch in evidence for microscopic work tended to mask the increasing amounts of nitrogenous reserve material.

3. Disorganization of Nuclei. The various changes in the endosperm nuclei in the later stages of development were studied on the 1904 material chiefly by means of series of hand-sections stained with Delafield's haematoxylin.

As we have seen, starch has filled into practically all the endosperm cells a fortnight before the grain can be regarded as ripe enough to cut, but the curves illustrating the inflow of carbohydrates show that starch continues to be crammed into the cells for some while longer. Just about the time that all the endosperm cells have received some quota of their starch, when the grain is just beginning to turn from green to brown, changes occur in the nuclei of the cells. Up to this period these have remained perfect and complete, rather large in proportion to the size of the cells, possessing good nucleoli and taking stains well. Those nuclei in the neighbourhood of the embryo are the first to exhibit change, in fact disorganization seems to proceed gradually from the tip downwards, in exactly the opposite direction to that in which the starch is deposited. First of all the nuclei in the middle of the flanks seem to lose their nucleoli and become very dense in structure, staining more deeply than those near the aleurone layer, which still retain their nucleoli. This change continues downwards and outwards as time goes on, though some of the nuclei in the sub-aleuronic cells round the furrow retain their nucleoli till quite a late stage in maturation. While this is going on a further alteration occursthose nuclei which first become dense apparently lose their solidity, and exhibit a network structure in section, at first appearing as very coarse networks, with thick walls and relatively small cavities, later as fine reticula with large cavities. Investigation showed that this is due to the pressure 
of the surrounding carbohydrates. At first the dense nuclei become somewhat deformed, as the neighbouring starch grains begin to press upon them, making dents in the nuclear matter. As the pressure from without increases the substance of the nucleus is squeezed out between the starch grains, eventually surrounding and enclosing them. The method of procedure might be illustrated by taking small balls of putty and pushing peas into them. A section across such a ball would resemble the 'network' nuclei of the wheat grain -if only a few peas were present, the putty would appear as a thick-walled network, while if the peas were in contact the matrix of putty would be well spread out into quite a fine reticulum, filling up the interspaces between the intruding bodies.

This later stage in nuclear disorganization follows the same course as the initial stage and spreads outwards and downwards, though many of the nuclei in the sub-aleuronic layer never get so far, simply losing their nucleoli and becoming dense, but not being subjected to the intrusion of starch grains. The nuclei which are furthest advanced in disorganization, showing an exceedingly attenuated reticulum, do not stain at all well, and need careful observation in some cases if they are not to be overlooked.

This disorganization is by no means completed by the time the corn is cut, but continues its progress while it is standing in 'stook' previous to carrying. The Square Head's Master from Plot 3, Broadbalk, was cut on August 5, 1904, and carted on August I2. On the former date nuclear networks had spread as far downwards as the base of the embryo, below which solid nuclei still persisted. Seven days later, when carted, networks could be found right through the grain from top to bottom. Generally speaking, at this late stage in maturation the endosperm cells at the tip of the grain contained nuclei in only the very finest network stage; towards the lower end of the kernel, the networks occurred chiefly in the middle of the flanks and were coarser, while at this level the nuclei in the subaleuronic layers still remained in most cases dense and solid. These latter changes are evidently due to desiccation, which the analyses show to be a marked feature of the last stages of ripening, especially after the corn is cut, and not to the further influx of reserve food material. Two other varieties of wheat were examined with similar results, but in no case was such disorganization seen in any cells of the aleurone layer.

There is just a possibility that these facts may have some bearing on the problem of the vitality of the endosperm tissue, corroborating from the cytological standpoint some of the recent work on the subject. Miss Bruschi (15), fully admitting the vitality of the aleurone layer, maintains that only the immediately sub-aleuronic cells can be regarded as in any sense living, all the rest of the tissue being quite dead. As we have seen, the nuclear networks in the mass of endosperm tissue only stain very 
slightly in the later stages, while most of the sub-aleuronic cells retain dense nuclei to the end. This may indicate that the nuclei which stain so slightly are to all intents and purposes dead, while the others still retain at least some degree of vital energy; but such a suggestion can only be brought forward with the utmost reserve, because at the time that the nuclear networks are forming the wheat grains are undergoing considerable desiccation, and so the pressure on the tissues is probably increased by shrinkage. It may easily happen that the desiccation also affects the nuclei, and the loss of staining power may be due to mere physical changes partly caused by the withdrawal of water.

A similar phenomenon, due to the squeezing action of starch grains, has been noticed in barley by Brown and Escombe (16), who describe the 'senescence' and disintegration of the nuclei of the endosperm as maturity approaches. According to these authors, deformation of the nucleus begins in the cells underlying the sub-aleuronic layer, and rapidly advances centripetally till nearly the whole of the endosperm is involved, the deformation being followed by complete disintegration of the nucleus. In the later stages of ripening, the cells of the sub-aleuronic layer also become involved, the very last cells to undergo this 'nuclear senescence' being those of this layer in the ventral folds on either side of the furrow. This may be paralleled in the wheat, in which the nuclei in this same position are the last to lose their nucleoli and become dense in structure, but the complete disintegration observed in barley does not occur in Triticum, as the fine networks can be made out to the end.

The way in which the disintegration proceeds throughout the length of the grain is not touched on by Brown and Escombe, so it is possible that a more complete examination would reveal some nuclei remaining at the further end of the grain which would compare with the dense subaleuronic nuclei of the wheat.

\section{(d) Development of the Embyro.}

Strasburger (13) gives a very complete account of the structure of the embryo in the ripe seed, but does not enter into the developmental history. The egg cell after fertilization enters on a short period of rest till about the fifth day after pollination, when the first division occurs. Koernicke mentions a three-celled stage as being much in evidence, but unfortunately the material does not show it.

The youngest segmented embryo observed consisted of a mass of four or five cells apparently attached to another cell nearer the micropyle, presumably the suspensor, but the preparations were not sufficiently clear to be certain of this point.

During the next eight or nine days cell-division proceeds actively, and the young embryo develops into a mass of cells, rapidly increasing in size. 
At first it is absolutely undifferentiated, but later on the cells at the periphery arrange themselves to form a definite surface layer. About a fortnight after pollination the first traces of differentiation can be made out; towards the tip of the grain the cells in the middle begin to group themselves into a central core, while lower down the initials of the cotyledons appear in the form of two slight projections on the dorsal side of the embryo away from the endosperm. These projections grow towards one another and eventually meet, closing round the inner mass of tissue which forms the rudimentary shoot and shows nuclei in active division; in

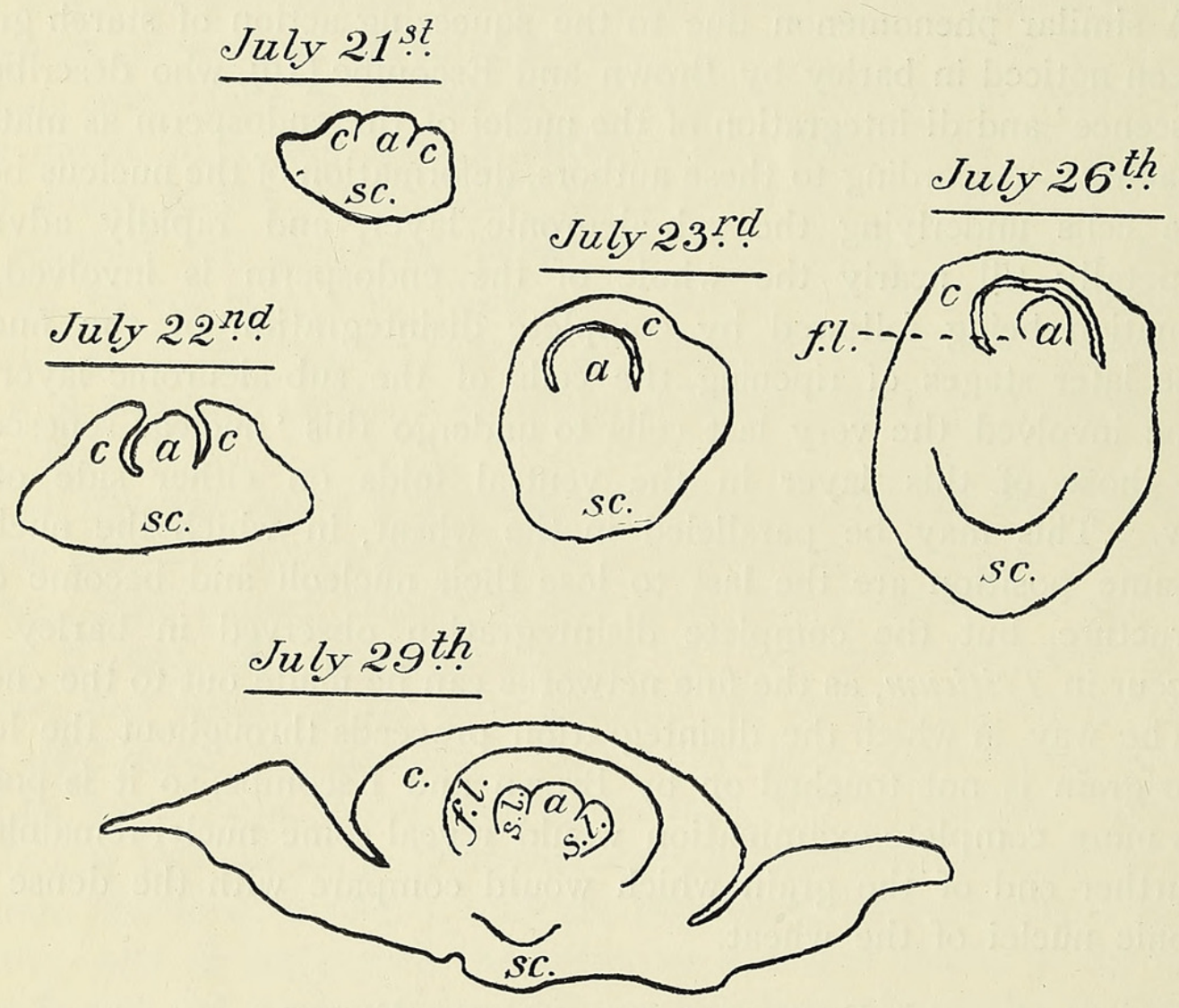

TEXT-FIG. 4. Outline sketch showing development of plumule in grains pollinated on July 6 , I907. c. cotyledon; f.l. Ist leaf; s.l. 2nd leaf; sc. scutellum; a. axis of young shoot. T.S. $\times 62$.

about three days' time the edges of the cotyledon not only meet but fuse, so forming a kind of false tube, which, however, gives an indication of its real derivation in the fact that the two edges always remain free quite at the tip.

Meanwhile the central core has become more clearly marked out, and about six days from its first appearance the young radicle begins to separate from the surrounding tissue, which forms the coleorhiza or root-sheath. Just at this time the first traces of the epiblast appear-the ligule which develops on the hypocotyl immediately above the radicle, on the dorsal side of the embryo. A little later the tissues of the radicle are seen 
to be arranging themselves into epidermis, cortex, and vascular cylinder. Meanwhile the root-cap has been evolving itself, and is now quite clear.

Rather less than four weeks after pollination the first pair of rootlets come into being. These are arranged right and left of the radicle, but rather towards the outer side of the embryo, and arise from the very base of the hypocotyl, just where it joins the young root. About a week later two other rootlets appear above the first pair, with practically the same orientation, but a trifle more dorsal. In the course of another week a fifth rootlet makes its appearance, lying between the others on the outer side, which does not seem to be mentioned by Strasburger. No further root development occurs before the embryo enters upon its resting stage in the ripe seed.

Returning to the developing plumule-about three weeks after pollination the first leaf is marked out, with a divergence of $\frac{1}{2}$ from the cotyledon, with the free tips pointing inwards towards the endosperm. This leaf makes far more growth than any of the subsequent ones, so that eventually its edges are folded over one another at the tip, the lower part forming a tube. Other leaves are soon marked out, so that by the time the grain is ripe three or four are in evidence, all with a divergence of $\frac{1}{2}$.

When the radicle and plumule start differentiating the embryo begins to shape itself. The tissue lying between these rudiments and the endosperm gradually spreads itself out into a shield-like mass forming the scutellum, which develops a well-marked epithelium towards the endosperm, and acts as a sucking organ at the time of germination. This spreads upwards and downwards, as well as laterally, so that at length the young plant appears to be borne on the outer face of the shield.

The initials of the embryonic vascular system are marked out at quite an early stage, when the epiblast begins to develop and at the same level with it. At first a strand of differentiated cells appears in the hypocotyl, which strand turns out into the scutellum, running in it for some way parallel to the plumule, and finally disappearing. As time goes on this vascular strand gets more clearly marked out, and continues its way through the scutellum below the level of the plumule. When first it passes from the hypocotyl the cells are somewhat hexagonal in cross-section, but lower down they appear elongated, with the long axis at right angles to the ventral edge of the scutellum. At length this strand begins to spread out laterally, till eventually a fan-like arrangement of conducting cells is formed, which continues nearly to the extreme end of the scutellum.

Soon after the initials of the vascular strand appear in the hypocotyl branches pass off from it, one into either side of the cotyledon, but these two branches undergo no further division, remaining intact throughout development. In due course vascular strands also pass into the first leaf, 


$$
\text { July } 25^{t h}
$$

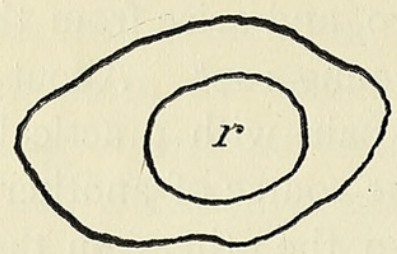

July $31^{\text {st. }}$
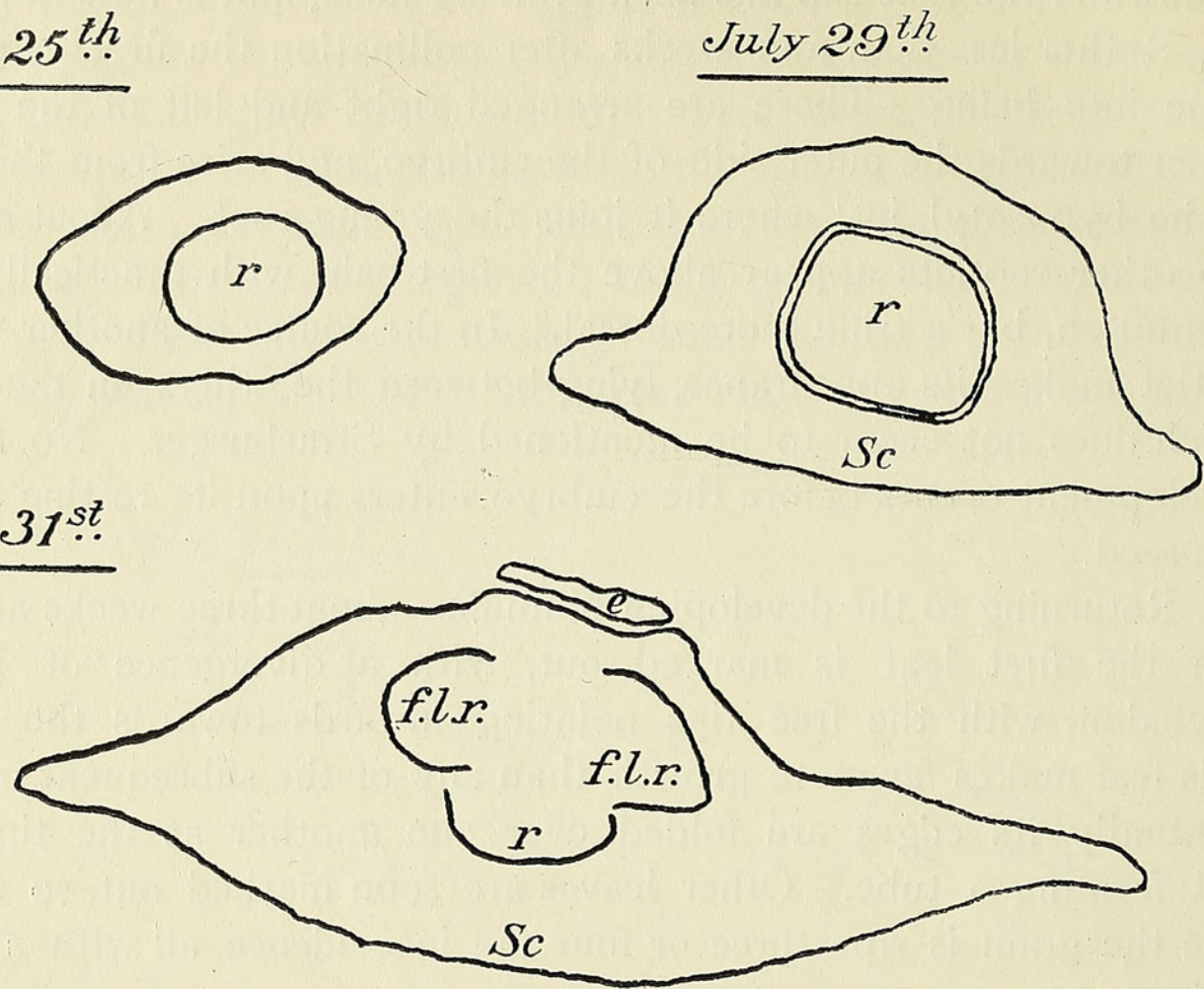

(Aug.11 the
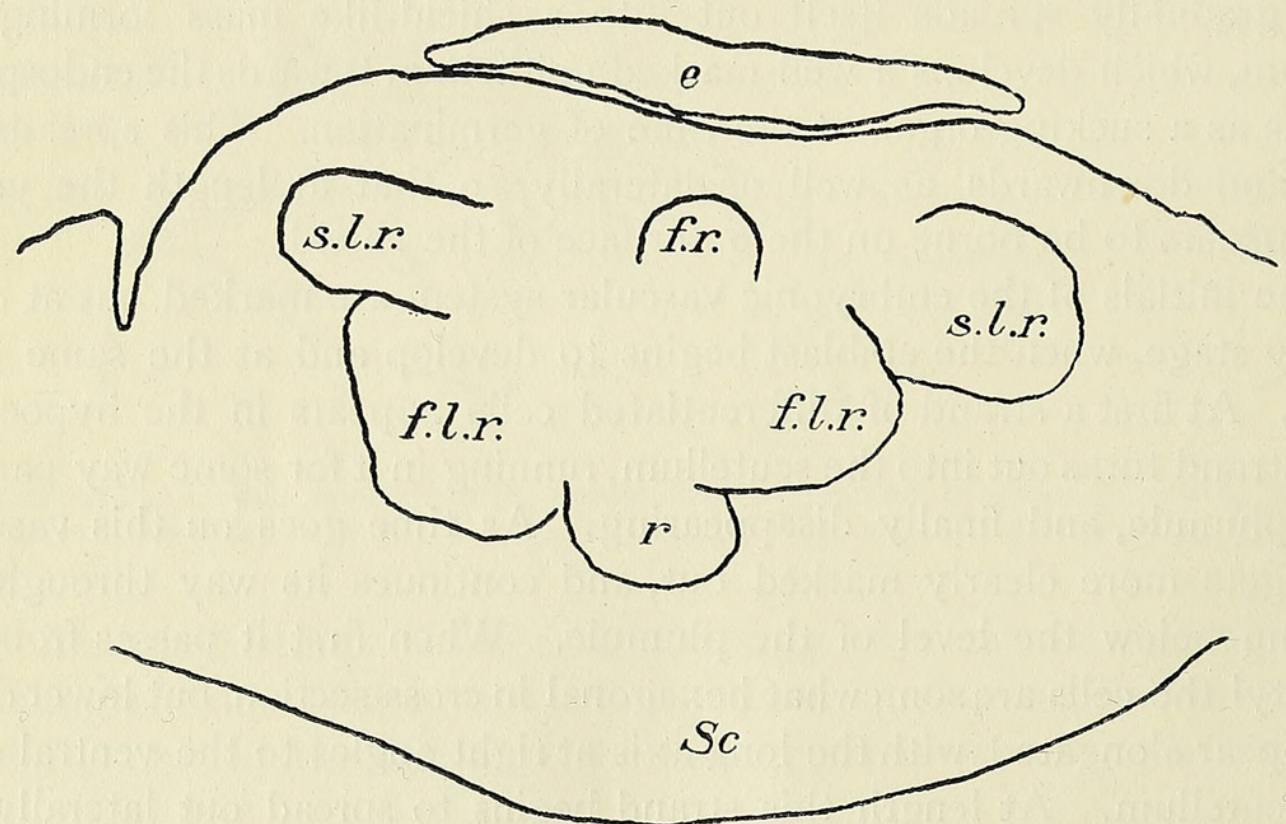

TEXT-FIG. 5. Outline sketch showing development of radicle and rootlets in grains pollinated on July 6, 1907. The last stage was obtained from 1904 material, but would probably correspond in age to grains gathered on August II, I907. $r$. radicle; f.l.r. first pair of lateral rootlets. s.l.r. second pair of lateral rootlets; f.r. fifth rootlet ; $e$. epiblast; sc. scutellum. Radicle is only marked out on July 25 , not separated from the surrounding tissue. T:S. $\times 62$. 
but these divide up till eventually about a dozen are present, and the leaf shows definite ribbing on its inner side. Traces of vascular tissue can also be made out in the second leaf by the time its development is completed.

When the seed germinates the radicle first shows itself, pushing its way through the tissues of the coleorhiza, which remains as a sheath at its base. The two pairs of lateral rootlets appear at intervals, the lowest pair first, and rapidly elongate till they are soon as well marked as the main root. Very much later the solitary fifth rootlet emerges, coming out from between the upper pair of laterals. No tap-root is formed, since the adventitious rootlets develop as strongly as the radicle, and so a fibrous root system is ultimately the result.

\section{SUMMARY.}

I. No cytological differences can be observed between wheat grains of different varieties, grown under similar conditions, which produce flour of varying strengths.

2. No cytological differences, indicative of strength, are to be found in the developing grains of one variety of wheat, when grown in the same field, on similar soil, and under the same climatic conditions, but subject to radical differences in manuring.

3. The reputed difference in strength between grains of the same variety, grown under the same conditions, but cut 'green' and 'dead ripe', is not associated with any significant cytological change.

4. Examination of the different grades of flour obtained during the various processes of roller milling show that the cells of the aleurone layer very rarely get into the flour, but remain attached to the bran in small sheets.

5. The endosperm arises in the first place by free-cell-formation, but after about a week wall-formation begins, starting from the periphery of the embryo-sac and proceeding inwards, while the central vacuole fills up first at the micropylar end. The peripheral layer is marked off about a fortnight after pollination, and develops into the aleurone layer.

6. Deposition of starch grains begins in the middle of the flanks of the endosperm at the lower end of the grain, and proceeds upwards and outwards. In the bridge the cells nearest the furrow are the first to fill up, the deposition proceeding from this point towards the dorsal side of the grains. Reserve nitrogenous material enters at the same time as the starch.

7. During the process of maturation, disorganization of endosperm nuclei takes place, caused by the increasing pressure of the surrounding food substances, which is largely due to the desiccation going on at this stage. The nuclei lose their nucleoli, become deformed, and finally 
appear as very fine networks spread out between the intruding starch grains.

8. The development of the embryo is normal. A fifth lateral rootlet is formed in addition to the two pairs of laterals usually described, lying between them on the dorsal side, which does not appear in germination until quite late, after the other rootlets and the plumule are well developed.

In conclusion, I have to express my thanks to Mr. A. D. Hall, at whose suggestion the work was undertaken, for the valuable advice he has given me all through the progress of the investigation.

November, 1908.

\section{LITERATURE CITED.}

1. Guthrie : History of a Grain of Wheat. Depart. of Agric., New South Wales, Misc. Pub. 529.

2. Hamann, G. : Die Backfähigkeit des Weizenmehles und ihre Bestimmung. Heidelberg, I902.

3. Biffen, R. H. : Mendel's Law of Inheritance and Wheat Breeding. Journ. Agric. Sci., vol. i, Part I, I 905 .

4. Wood, T. B.: The Chemistry of Strength of Wheat Flour. Journ. Agric. Sci., vol. ii, Parts II and III. I907.

5. Hall, A. D. : Report of Home-grown Wheat Committee, igo6.

6. Report of Home-grown Wheat Committee, I904.

7. Cannon, W. A.: A Morphological Study of the Flower and Embryo of the Wild Oat, Ave fatua. Proc. Calif. Acad. Sci., iii, I900.

8. KoERNiCKE, M. : Untersuchungen über die Entstehung und Entwickelung der Sexualorgane von Triticum mit besonderer Berïcksichtigung der Kerntheilung. Verhandl. Naturhist. Ver. d. Preussischen Rheinl. I 896.

9. Guignard, L. : La double fécondation dans le maïs. Journ. Botanique, igor.

10. Golinski, St. J. : Ein Beitrag zur Entwicklungsgeschichte des Androeceums und des Gynoeceums des Gräser. Bot. Centralbl., I893.

11. Westermaier, M.: Zur Embryologie der Phanerogamen, insbesondere über die sogenannten Antipoden. Nova Acta Leopoldina, 1890.

12. Maurizio, A. : Getreide, Mehl und Brot, I903.

13. Strasburger, E. : Das Botanische Practicum, i 887 .

14. Volle R, W. R. : Modern Flour-milling.

15. Bruschi, D. : Researches on the Vitality and Self-digestion of the Endosperm of some Graminaceae. Ann. Bot., July I908.

16. Brown and Escombe : Trans. Guinness Research Lab., vol. i, Part I, I903, pp. I 23-7. 


\title{
EXPLANATION OF FIGURES IN PLATES VIII AND IX.
}

\author{
Illustrating Miss Brenchley's Paper on the Grain of Wheat.
}

Abbreviations used : $o$. ovum; sy. synergid; $g . n$. generative nucleus; $e . n$. endosperm nuclei ; e.s. embryo sac; p.t. pollen tube; $d$. deeply-staining bodies in pollen tube; $e p$. nuc. limiting layer or nuclear epidermis; ov. integ. ovular integuments; $p l$. placenta; $p c$. pericarp; nuc. nucellus; end. endosperm; st. end. starchy endosperm; a.l. aleurone layer; st. starch grains ; sc. ordinary cells of scutellum; v.s. conducting strand in scutellum; m. micropylar end of e.s.; pm. protoplasm of e.s. ; emb. embryo; $f$. furrow of grain; $r$. radicle; f.l.r. first pair of lateral rootlets ; s.l.r. second pair of rootlets; f.r. fifth rootlet; c. cotyledon; f.l. first leaf; s.l. second leaf; w. germinating wheat grain; T.S. transverse section ; L.S. longitudinal section.

\section{PLATE VIII. FIGS. I-I6.}

Fig. I. Rather oblique section through embryo-sac about two days after pollination. Enclosed in the ovum is a dark mass which probably is the male generative nucleus which has not yet lost its individuality. Two nuclei are present at the other side of the sac, the result of the first division of the definitive nucleus. $\times 270$. $\times 260$.

Fig. 2. The adjacent section to Fig. I, showing the tip of the pollen tube overlying the ovum.

Fig. 3. Part of T.S. of e.s. three days after pollination. The cells of the nucellar epidermis have renewed their activity and the nuclei are in process of division. $\times 270$.

Fig. 4. Part of L.S. through e.s. six days after pollination, showing the numerous endosperm nuclei embedded in the protoplasmic lining which surrounds the central vacuole. $\quad \times \quad$ I 70.

Fig. 5. L.S. through e.s. seven or eight days after pollination. Cell wall formation is proceeding inwards from the periphery of the endosperm, but the cells are not complete in the middle. $\times$ I 7 .

Fig. 6. Part of T.S. of grain eight days after pollination. Remains of the thin-walled nucellus still occur between the nucellar epidermis and the endosperm. $\times 270$.

Fig. 7. T.S. ten days after pollination. Thin-walled nucellus has entirely disappeared. $\times 270$.

Fig. 8. T.S. fourteen days after pollination. The nucellar epidermis is losing its cell contents, and the outer layer of the endosperm is marked ont to form the future aleurone layer. $\times 270$.

Fig. 9. T.S. nineteen days after pollination. Aleurone layer clearly marked out. $\quad \times 270$.

Fig. Io. T.S. of mature grain, showing endosperm fully developed. $\times 270$.

Fig. II. T.S. Perfect endosperm nuclei, with nucleoli. $\times 320$.

Fig. I 2. T.S. Endosperm nuclei rather deformed by pressure; no nucleoli. $\times 320$.

Fig. I3. T.S. Endosperm nuclei in 'coarse network' stage. $\times 3^{20}$.

Fig. I 4. T.S. Endosperm nuclei in 'fine network' stage. $\times 320$.

Fig. I 5. T.S. of scutellum one week before the corn was cut, showing the conducting strand just after it has turned out from the hypocotyl-cells roughly hexagonal in T.S. Cell contents omitted. $\times$ I80.

Fig. I6. Same embryo as Fig. I5, showing conducting strand at a point lower down the grain, where the cells are elongated in T.S. On one side the strand is just beginning to spread out laterally. Cell contents omitted. $\times$ I80.

\section{PLATE IX. Figs. I7-23.}

Fig. I7. Same embryo as Fig. I5, but lower down than Fig. I6, where the conducting strand has spread out in a fan-like manner. Cell contents omitted. $\times$ I8o.

Figs. I 8-23. Six successive stages in germination, showing the order of development of the rootlets. About natural size.

N.B.-In Figs. 4, 5, 6, 7 the endosperm has somewhat shrunk away from the surrounding tissues in the course of preparation. 
Annals of Botany,

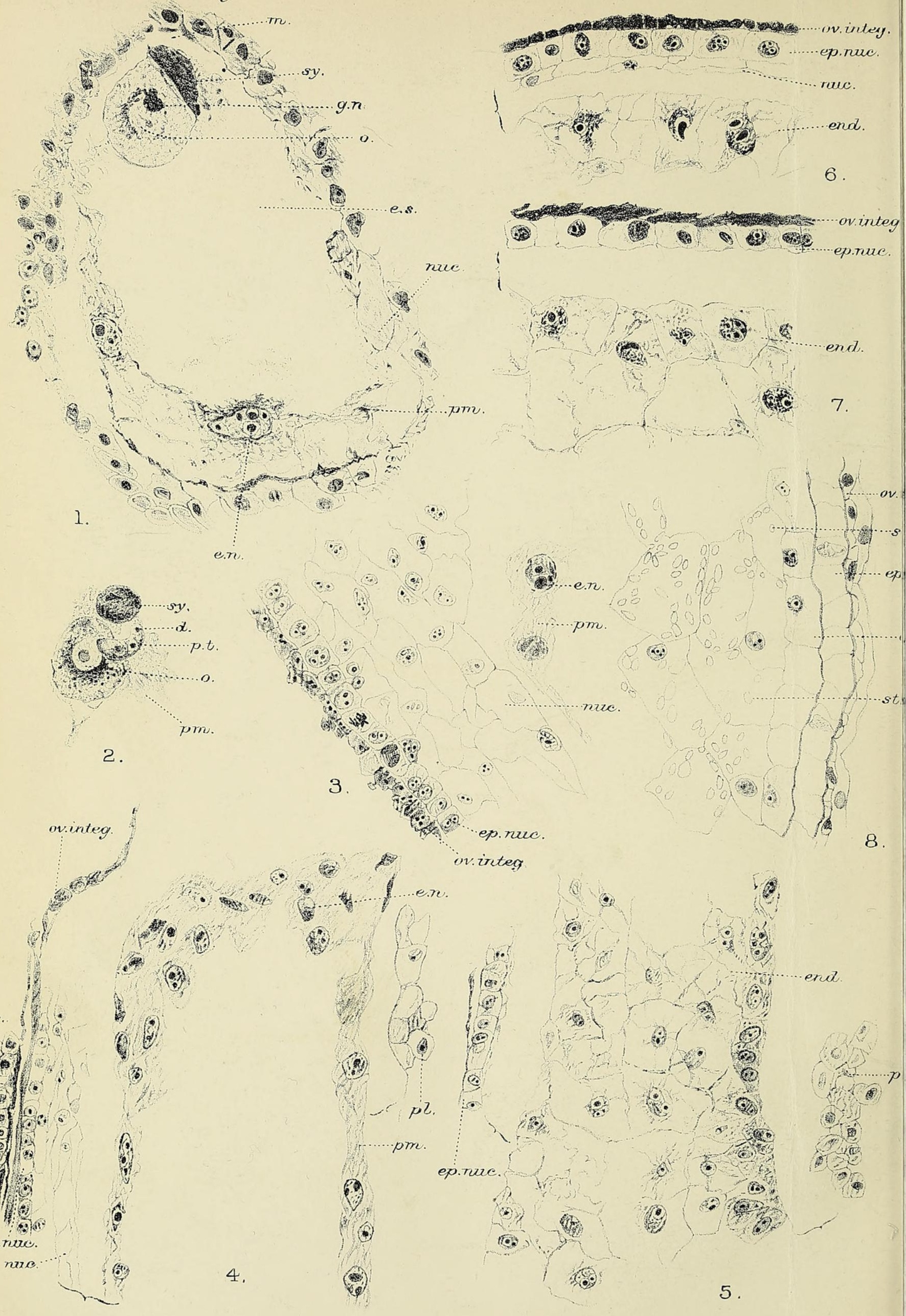

W.E.B. del. 
$\underbrace{(6)}_{10}$

a.
8. 8 on

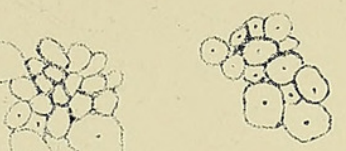

$80^{2}$

280.06

14.
12

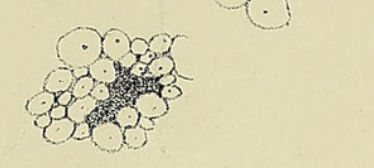

12.

VIZ. XXIII, PU. VIII.
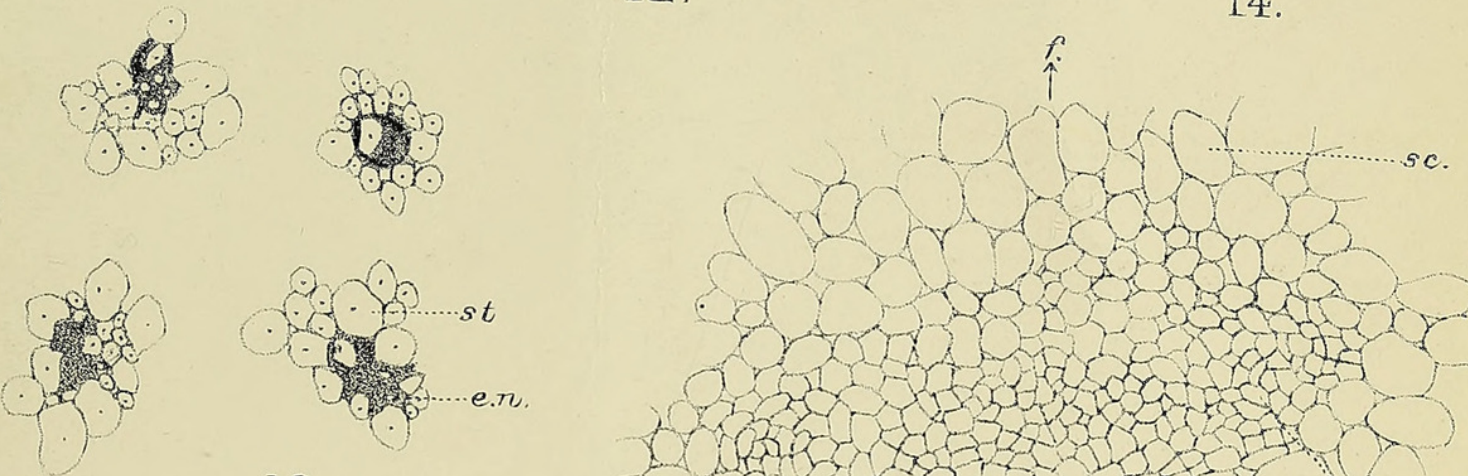

13.

2.18\%

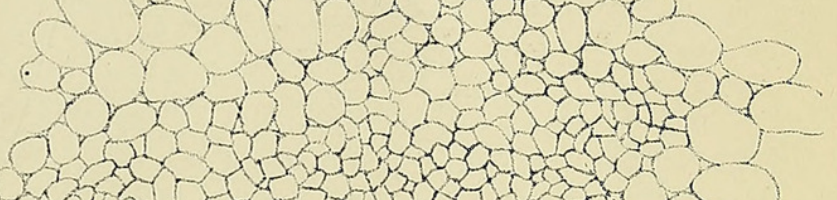

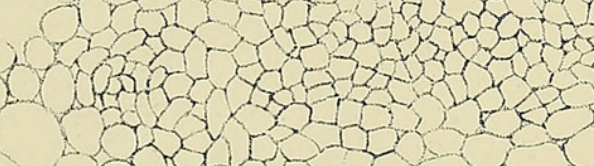
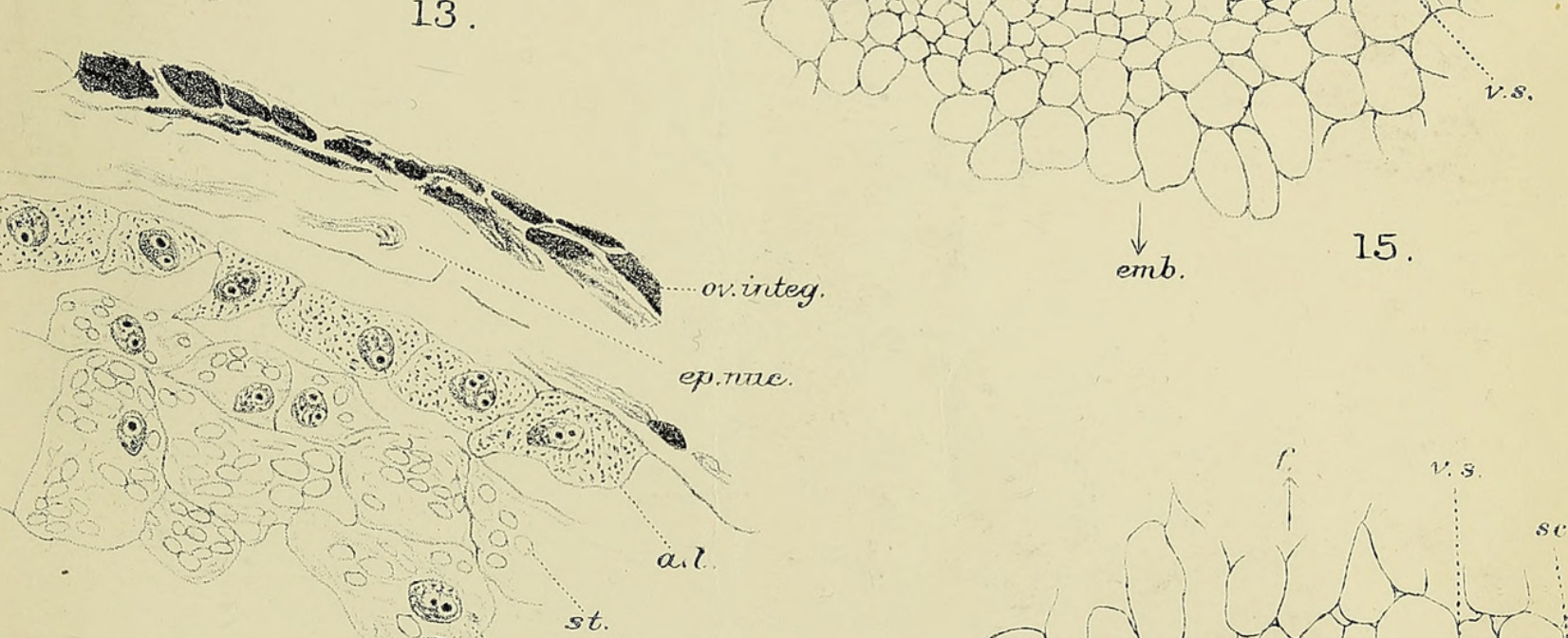

$9 . \quad$ st. end.

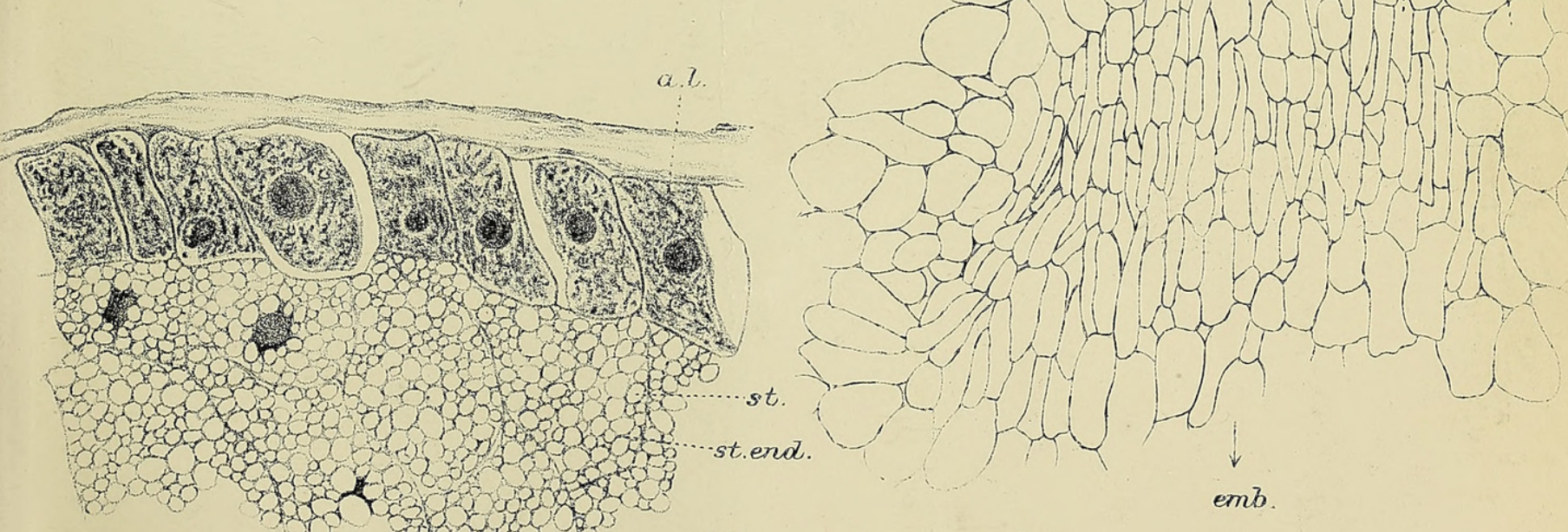

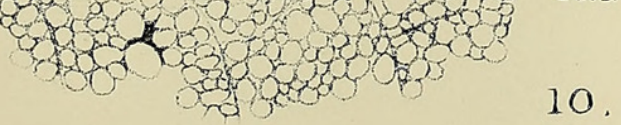

16. 

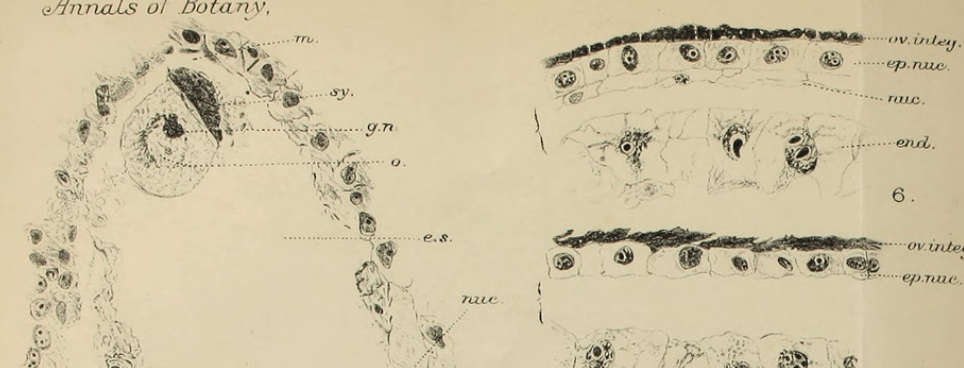

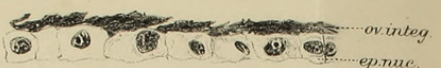

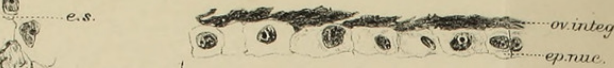

8

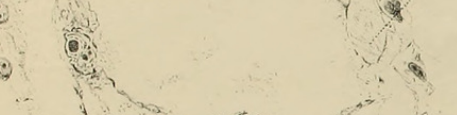

8. Ther का

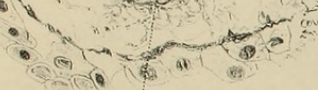

(et sy. $\%$ s. $^{2}$ (e)

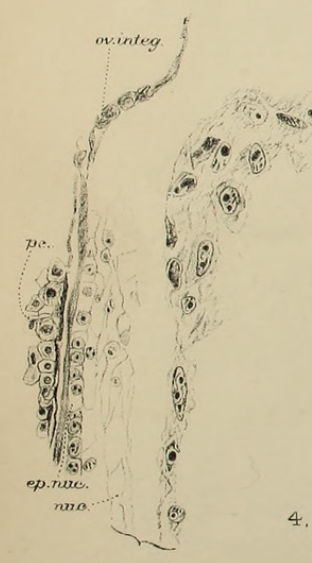

WL.B. dal.

\section{4.4 end.}

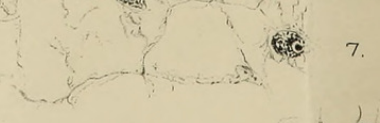

(a) e.n

क्षे Top rouc

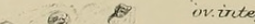$$
\text { oviriteg }
$$$$
\text { (4) } 6
$$

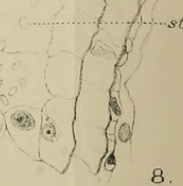
3.

(1) ovinteg (a)

(i.)

11.

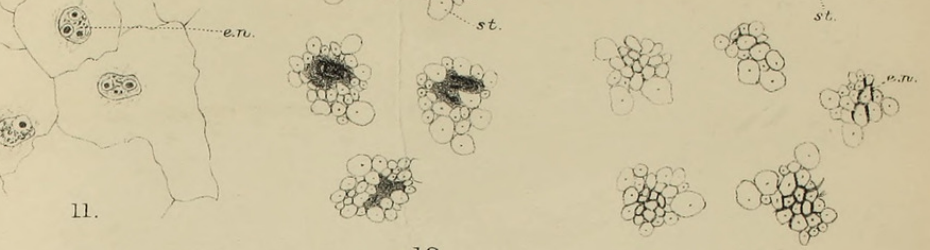

14.
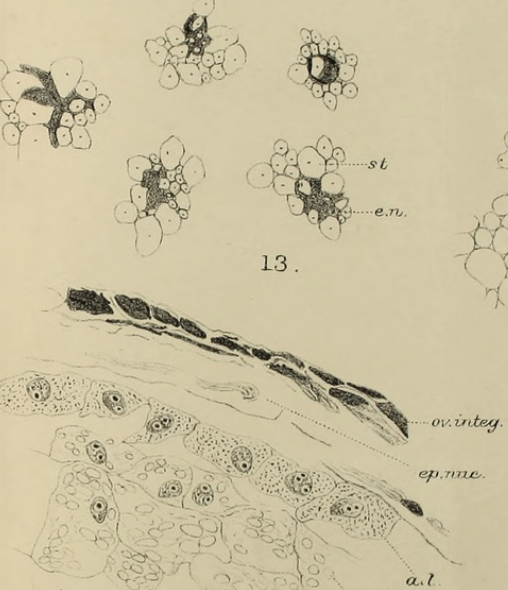

13.
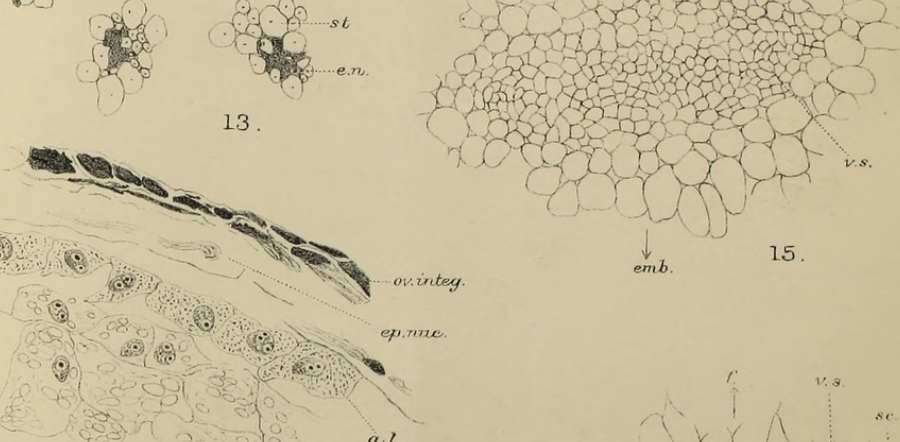

$$
\text { ta }
$$

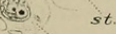

st. end.
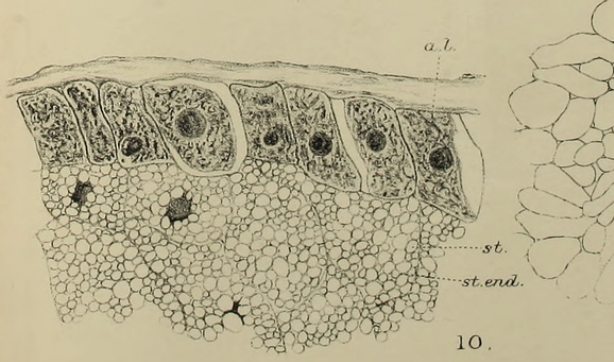

16 
Anrals of Botany.

Vol.XXIII,Pl.IX.

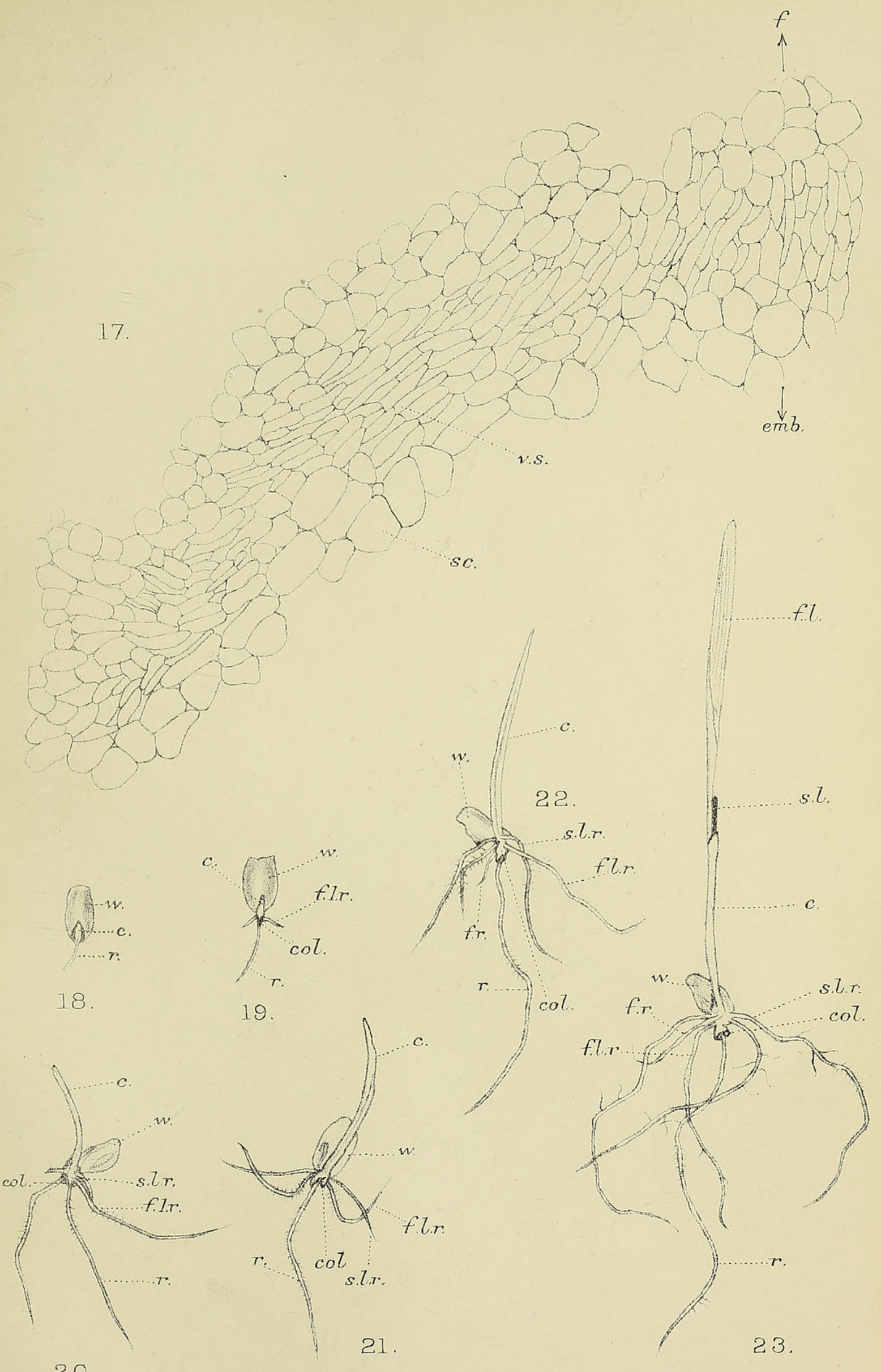

20. 


\section{$2 \mathrm{BHL}$ Biodiversity Heritage Library}

Brenchley, Winifred E. 1909. "On the strength and development of the grain of wheat (Triticum vulgare)." Annals of botany 23, 117-139. https://doi.org/10.1093/oxfordjournals.aob.a089202.

View This Item Online: https://www.biodiversitylibrary.org/item/236540

DOI: https://doi.org/10.1093/oxfordjournals.aob.a089202

Permalink: https://www.biodiversitylibrary.org/partpdf/318941

\section{Holding Institution}

Smithsonian Libraries

\section{Sponsored by}

Biodiversity Heritage Library

\section{Copyright \& Reuse}

Copyright Status: Not in copyright. The BHL knows of no copyright restrictions on this item.

This document was created from content at the Biodiversity Heritage Library, the world's largest open access digital library for biodiversity literature and archives. Visit BHL at https://www.biodiversitylibrary.org. 